\title{
УДК: 612.825.8+613.685
}

\section{ПСИХОФИЗИОЛОГИЧЕСКИЕ ОСОБЕННОСТИ ВОЕННЫХ ВРАЧЕЙ РАЗНЫХ СПЕЧИААЬНОСТЕЙ}

\author{
Кальниш В.В., Ешенко В.И., Красовский В.В., ГАаАских К.А.
}

\author{
Украинская военно-медицинская акацемия, г. Киев
}

В статье представлены материалы изучения психофизиологических, психологических и социальных характеристик военных врачей. С помощью факторного анализа выделен перечень наиболее весомых факторов, отражающих комплексные свойства деятельности военного врача, учитывающих представительство и взаимодействие различных психофизиологических и психо-социальных характеристик человека. Установлены наиболее весомые факторы для хирургов (фактор эмоционально-волевых качеств, экономических ценностей и порядка, влияния окружающих) и терапевтов (фактор формирования коммуникативных возможностей, гуманистических и экономических ценностей, жизненной перспективы).

Ключевые слова: психофизиологические качества, военные врачи, ведущие факторы профессиональной деятельности

\section{Введение}

Коренное реформирование Вооруженных Сил Украины оказывает значительное влияние на формирование их медицинского обеспечения. Это связано с тем, что в профессиональной армии, наряду с лечебной деятельностью, значительно большее внимание будет уделяться проблемам профилактической медицины (профессиональному отбору, психофизиологическому сопровождению деятельности, реабилитационным и профилактическим мероприятиям и пр.). Существенное расширение разнообразия проводимых работ, повышение ответственности за результат деятельности, значительное нервно-эмоциональное напряжение, нерегулярная сменность и другие факторы существенно ужесточают требования к психофизиологическим качествам военных врачей.

Значительной роли нервно-психических нагрузок в формировании функционального состояния работников различных профессий уделяется большое внимание ведущими научными центрами многих стран [4, 6 и др.]. Одним из эффективных средств компенсации действия интенсивных нагрузок является профессиональный психофизиологический отбор. Такой отбор является действенным способом прогнозирования и успешности долгосрочной профессиональной деятельности врачей различных специальностей $[1,10]$. В научных статьях подчеркивается, что большое значение при проведении профессионального отбора имеет выявление социально-психологических аспектов деятельности и психофизиологических функций, на которые приходится наибольшая профессиональная нагрузка $[5,12]$.
По данным В.С.Новикова [8] из абитуриентов, поступавших в Военно-медицинскую академию (СПб) в 1998-1999 годах, лишь 10-13\% относились к 1 -й категории профессиональной пригодности и $45-50 \%-$ к 3 -й и 4-й категориям. Автор указывает, что среди лучших по успеваемости слушателей академии более $90 \%$ курсантов имеют 1-ю и 2 -ю категории профессиональной пригодности. Подавляющее большинство слабо успевающих или менее дисциплинированных курсантов составляют лица, условно пригодные к обучению в академии. Қак правило, до 70\% курсантов 3-й категории профессиональной пригодности не сдают своевременно экзамены ввиду имеющихся академических задолженностей. Поэтому зачисление на учебу курсантов, не пригодных к обучению, можно рассматривать как необоснованную трату средств.

Қак уже подчеркивалось, для проведения адекватного профессионального отбора врачей необходимо детальное изучение их деятельности $[2,11]$. Поэтому актуальным является выделение особенностей их психофизиологического статуса, необходимого для уточнения правил профессионального психофизиологического отбора.

Цель работы - выявление психофизиологические особенностей военных врачей разных специальностей, повышающих свою квалификацию в высшем учебном заведении.

\section{Методы и объем исследования}

Исследования были проведены на 122 экспертах-слушателях Украинской военно-медицинской академии (УВМА), специализирующихся в области хирургии, терапии, анестезиологии, стоматологии, 
гигиены, психофизиологии, фармации и общей практики. Для определения требований военноврачебной деятельности к психофизиологическим качествам работника был использован опросник К.Қ.Платонова «Модифицированная карта личности» [3], состоящий из 96 10-балльных вопросов, объединенных в 33 группы шкал, отражающих психофизиологические особенности человека и его отношение к психо-социальным факторам внутренней и внешней среды. Статистический анализ данных: вариационный, однофакторный дисперсионный, факторный и корреляционный виды анализа были проведены с помощью стандартного пакета программ STATISTICA 6.0.

\section{Результаты исследований и их обсуждение}

По свидетельству авторов, изучающих вопросы профессиографии медицинских специальностей, изучаемые врачебные профессии можно условно разделить на три группы: хирургические, терапевтические специальности и организация здравоохранения [2]. Поскольку в УВМА наиболее многочисленными являются хирургические и терапевтические специальности, именно им было уделено наибольшее внимание. Результаты опроса слушателей по трем группам шкал (психофизиологические качества, отношение к социально значимым факторам и отношение к психологически значимым факторам) представлены в табл. 1-3.

Из таблицы 1 видно, что оценка выраженности определенных психофизиологических качеств у хирургов и терапевтов несколько различаются. Так, наиболее важными качествами хирургов эксперты считают: мыслительные, волевые, языковые, атенционные (относящиеся к вниманию) и сенсорноперцептивные. Наименее выраженными являются: эмоциональные, имаженативные (относящиеся $\mathrm{K}$ образному мышлению) и коммуникативные качества. Для врачей-терапевтов порядок выраженности психофизиологических качеств несколько иной: мыслительные, языковые, волевые, имаженативные, атенционные. Наименее выраженными являются: эмоциональные, психомоторные и мнемические (относящиеся к памяти) качества. Выявленные различия, по-видимому, отражают специфику каждой из анализируемых врачебных специальностей. Например, для врачей-хирургов более важными являются (отличаются на 2 позиции в ранге факторов): сенсорно-перцептивные, психомоторные качества, а для врачей-терапевтов - имаженативные и коммуникативные качества.

Существенное сходство наблюдается и в степени выраженности отношения к определенным социально значимым факторам (табл. 2). Это сходство подчеркивает отношение врача к своей профессии. Для хирургов важным является отношение: к другим людям, к труду, к порядку, к уровню трезвости, к общественной жизни. Терапевты характеризуются высокими баллами по отношению: к другим людям, к работе, к порядку, к материальным ценностям, к уровню трезвости. Вместе с тем имеются определенные особенности этих профессиональных групп, характеризующиеся отличием степени выраженности факторов ( 2 и более позиций в иерархии факторов).

Для врачей-хирургов более значимым является отношение: к себе, к критике, к одежде. Врачи-те-

Іаблแща 1

Выраженность психофизиологических характеристик военных врачей разных специальностей (средняя \pm ошибка, баллы)

\begin{tabular}{|c|c|c|c|c|c|}
\hline \multirow{3}{*}{$\begin{array}{l}\text { № } \\
\text { n/n }\end{array}$} & \multirow{3}{*}{$\begin{array}{c}\text { Психологические } \\
\text { качества }\end{array}$} & \multicolumn{4}{|c|}{ Специальность } \\
\hline & & \multicolumn{2}{|r|}{ хирурги } & \multicolumn{2}{|c|}{ терапевты } \\
\hline & & оценка & $\begin{array}{c}\text { степень } \\
\text { выраженности, ранг }\end{array}$ & оценка & $\begin{array}{c}\text { степень } \\
\text { выраженности, ранг }\end{array}$ \\
\hline$\overline{1}$ & Сенсорно-перцептивные & $7,62 \pm 0,36$ & 5 & $7,52 \pm 0,33$ & 7 \\
\hline 2 & Психомоторные & $7,41 \pm 0,24$ & 6 & $7,16 \pm 0,18$ & 9 \\
\hline 3 & Атенционные & $7,92 \pm 0,35$ & 4 & $7,80 \pm 0,19$ & 5 \\
\hline 4 & Мнемонические & $7,14 \pm 0,34$ & 7 & $7,22 \pm 0,30$ & 8 \\
\hline 5 & Имаженативные & $6,89 \pm 0,54$ & 9 & $7,83 \pm 0,30$ & 4 \\
\hline 6 & Мыслительные & $8,24 \pm 0,26$ & 1 & $8,13 \pm 0,18$ & 1 \\
\hline 7 & Эмоциональные & $6,69 \pm 0,25$ & 10 & $6,87 \pm 0,16$ & 10 \\
\hline 8 & Волевые & $8,05 \pm 0,32$ & 2 & $7,83 \pm 0,25$ & 3 \\
\hline 9 & Коммуникативные & $7,05 \pm 0,28$ & 8 & $7,61 \pm 0,28$ & 6 \\
\hline 10 & Речевые & $8,05 \pm 0,29$ & 3 & $8,03 \pm 0,22$ & 2 \\
\hline
\end{tabular}


Таблแщ 2

Отношение к социально значимым факторам военных врачей разных специальностей (средняя \pm ошибка, баллы)

\begin{tabular}{|c|c|c|c|c|c|}
\hline \multirow{3}{*}{$\begin{array}{l}\text { № } \\
\text { n/n }\end{array}$} & \multirow{3}{*}{$\begin{array}{c}\text { Социально-значащие } \\
\text { качества }\end{array}$} & \multicolumn{4}{|c|}{ Специальность } \\
\hline & & \multicolumn{2}{|r|}{ хирурги } & \multicolumn{2}{|c|}{ терапевты } \\
\hline & & оценка & $\begin{array}{c}\text { степень } \\
\text { выраженности, ранг }\end{array}$ & оценка & $\begin{array}{c}\text { степень } \\
\text { выраженности, ранг }\end{array}$ \\
\hline 11 & К труду & $8,72 \pm 0,27$ & 2 & $8,45 \pm 0,21$ & 2 \\
\hline 12 & К окружающим & $7,25 \pm 0,26$ & 10 & $7,48 \pm 0,19$ & 8 \\
\hline 13 & K себе & $7,74 \pm 0,33$ & 7 & $7,22 \pm 0,20$ & 11 \\
\hline 14 & К коллективу & $6,47 \pm 0,55$ & 13 & $7,48 \pm 0,48$ & 9 \\
\hline 15 & К незнакомым & $6,47 \pm 0,54$ & 12 & $7,17 \pm 0,46$ & 12 \\
\hline 16 & К критике & $7,68 \pm 0,46$ & 8 & $7,43 \pm 0,43$ & 10 \\
\hline 17 & К общественной жизни & $7,89 \pm 0,32$ & 5 & $7,87 \pm 0,41$ & 6 \\
\hline 18 & К материальным ценностям & $7,87 \pm 0,34$ & 6 & $8,17 \pm 0,26$ & 4 \\
\hline 19 & К деньгам & $7,53 \pm 0,28$ & 9 & $7,52 \pm 0,26$ & 7 \\
\hline 20 & К порядку & $8,68 \pm 0,36$ & 3 & $8,35 \pm 0,29$ & 3 \\
\hline 21 & К одежде & $6,95 \pm 0,40$ & 11 & $7,09 \pm 0,37$ & 13 \\
\hline 22 & К алкогольным напиткам & $8,42 \pm 0,38$ & 4 & $7,91 \pm 0,27$ & 5 \\
\hline 23 & К другим людям & $9,03 \pm 0,24$ & 1 & $8,85 \pm 0,24$ & 1 \\
\hline
\end{tabular}

рапевты сильнее ощущают оттенки отношения: к окружающим, к коллективу, к материальным ценностям, к деньгам.

Психологически значимые показатели также определяют дифференциацию врачей по специальностям (табл. 3).

Для хирургов значимым является отношение: к опеке и указаниям, к неудачам, к качествам активности, принципиальности, пытливости (общие характеристики личности), к мужеству, к новому. Терапевты характеризуются большей выраженностью отношения: к будущему, к опеке и указаниям, к качествам активности, принципиальности, пыт- ливости, к неудачам, к новому. Қак видно, по этим отношениям наблюдается значительное сходство изучаемых профессиональных групп. Существенно отличаются отношения у хирургов: к неудачам, к мужеству, к правилам и законам. У терапевтов более существенным является отношение к будущему, что характеризует их профессиональную специфику - длительное отслеживание состояния больного в случае проявления хронических заболеваний.

Резюмируя полученные материалы, необходимо отметить, что достоверные различия между одними и теми же факторами у представителей разных специальностей отсутствуют. Это свидетельствует о

Отношение к психологически значимым факторам военных врачей разных специальностей

Таблища 3 (средняя \pm ошибка, баллы)

\begin{tabular}{|c|c|c|c|c|c|}
\hline \multirow{3}{*}{$\begin{array}{l}\text { № } \\
\text { п/II }\end{array}$} & \multirow{3}{*}{$\begin{array}{c}\text { Психологические } \\
\text { качества }\end{array}$} & \multicolumn{4}{|c|}{ Специальность } \\
\hline & & \multicolumn{2}{|r|}{ хирурги } & \multicolumn{2}{|c|}{ терапевты } \\
\hline & & оценка & $\begin{array}{c}\text { степень } \\
\text { выраженности, ранг }\end{array}$ & оценка & $\begin{array}{c}\text { степень } \\
\text { выраженности, ранг }\end{array}$ \\
\hline 24 & К будущему & $7,58 \pm 0,53$ & 7 & $8,65 \pm 0,29$ & 1 \\
\hline 25 & К новому & $7,84 \pm 0,34$ & 5 & $8,17 \pm 0,31$ & 5 \\
\hline 26 & К неудачам & $8,32 \pm 0,32$ & 2 & $8,17 \pm 0,38$ & 4 \\
\hline 27 & К мужеству & $8,16 \pm 0,25$ & 4 & $8,09 \pm 0,29$ & 6 \\
\hline 28 & К риску & $6,95 \pm 0,52$ & 9 & $7,35 \pm 0,39$ & 8 \\
\hline 29 & К опеке и указаниям & $8,47 \pm 0,23$ & 1 & $8,48 \pm 0,32$ & 2 \\
\hline 30 & К правилам и законам & $7,74 \pm 0,37$ & 6 & $7,22 \pm 0,30$ & 9 \\
\hline 31 & К своему здоровью & $5,68 \pm 0,43$ & 10 & $6,57 \pm 0,43$ & 10 \\
\hline 32 & К суевериям & $7,21 \pm 0,51$ & 8 & $7,39 \pm 0,42$ & 7 \\
\hline 33 & Общие характеристики личности & $8,20 \pm 0,27$ & 3 & $8,33 \pm 0,22$ & 3 \\
\hline
\end{tabular}


значительной родственности изучаемых профессий. Различия наблюдаются только в порядке выраженности после ранжировки уровня факторов в порядке убывания.

Однофакторный дисперсионный анализ, осуществленный по фактору действия врачебной специализации, дал дополнительную информацию, характеризующую отношение врачей к изученным показателям. Обнаружено, что имеются два фактора, где проявляется существенное различие отношения экспертов к определенным качествам: отношение к трезвости и деньгам. Уровень оценок отношений к этим факторам нельзя рассматривать в терминах «худший-лучший», поскольку во всех случаях были получены высокие баллы по шкалам, характеризующим степень отрицательного отношения к алкоголю, а также степень бескорыстия и щедрости. Ранжировка различных специальностей по выраженности отвращения к алкоголю привела к таким результатам: хирурги, гигиенисты, врачи общей практики, стоматологи, терапевты, психофизиологи, провизоры, анестезиологи. Упорядочивание баллов по шкале бескорыстия и щедрости выявило такое распределение специальностей: гигиенисты, стоматологи, провизоры, психофизиологи, хирурги, терапевты, врачи общей практики, анестезиологи,

Қак ви́дно из приведенных данных, уровневые характеристики различных психологических и социальных параметров дают ценную информацию о психофизиологическом и социально-психологическом портрете врачей различных специальностей. Однако такие портреты затруднительно составить без учета степени взаимодействия различных «элементарных» характеристик личности. Такую дополнительную характеристику можно дать, используя факторный анализ, который позволяет выделить комплекс скрытых, независимых внутренних факторов, формирующих поведение врача. Внутри каждого выделенного фактора определяется перечень тесно взаимосвязанных параметров, способствующих его формированию и проявлению.

Результаты факторного анализа психофизиологических параметров хирургов и терапевтов приведены на рис. 1.

Қак видно из рис. 1, у хирургов выделены 2 фактора: $\mathrm{I}^{\mathrm{a}}(\mathrm{x})$ - фактор эмоцио- нально-волевых качеств, объясняющий $35 \%$ общей дисперсии, и $\mathrm{II}^{\mathrm{a}}(\mathrm{x})$ - фактор восприятия и хранения информации, детерминирующий $29 \%$ общей дисперсии анализируемых данных. Қак видно из приведенного рисунка, в фактор $\mathrm{I}^{\mathrm{a}}(\mathrm{x})$ входят характеристики внимания, мышления, эмоциональности и волевых качеств, а фактор II $^{\mathrm{a}}(\mathrm{x})$ представлен параметрами сенсорно-перцептивной сферы, памяти, коммуникации и языковых способностей.

Психофизиологический портрет терапевтов состоит из двух факторов: $\mathrm{I}^{\mathrm{a}}(\mathrm{T})$ - фактора формирования коммуникативных возможностей врача, объясняющий $38 \%$ общей дисперсии и формирующегося из показателей внимания, мышления, эмоциональности, воли, коммуникативных возможностей и языковых способностей человека; II ${ }^{\mathrm{a}}$ (т) - фактор, названный фактором формирования образов, который детерминирует $19 \%$ общей дисперсии имеющихся данных и состоит из характеристик сенсорно-перцептивной сферы и сферы формирования образов.

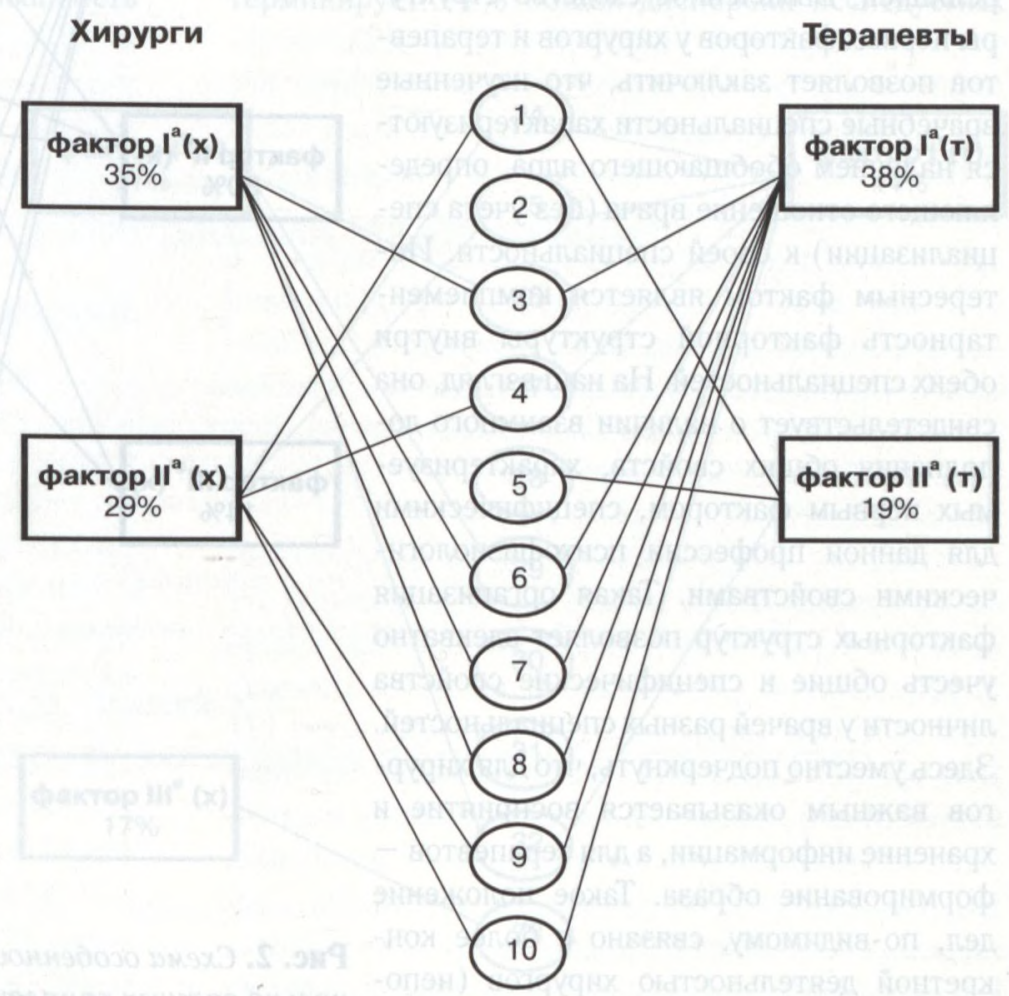

Рис. 1. Схема особенностей формирования скрытых профессионально важных комплексных факторов врачей хирургов и терапевтов по психофизиологическим показателям.

1-10 - психофизиологические характеристики, обозначенные в табл. 1.

$I^{a}(x)$ - фактор эмоционально-волевых качеств хирургов;

$I^{a}(x)$ - фактор восприятия и хранения информации хирургов;

$I^{a}(m)$ - фактор коммуникативных возможностей терапевтов;

$I^{a}(m)$ - фактор формирования образов у терапевтов. 
Қак видно из рисунка выделенные факторы у хирургов и терапевтов имеют ряд общих черт и различий. Для количественной оценки степени сходства выделенных факторов были рассчитаны парные коэффициенты корреляции между соответствующими факторными нагрузками. Установлено, что $\mathrm{I}^{\mathrm{a}}(\mathrm{x})$ по своей структуре противоположен $\mathrm{II}^{\mathrm{a}}(\mathrm{x})$ - парный коэффициент корреляции $-0,74$ $(\mathrm{P}<0,01)$. Наблюдается значительное сходство структуры I ${ }^{\mathrm{a}}(\mathrm{x})$ с I $\mathrm{I}^{\mathrm{a}}(\mathrm{T})$ - коэффициент корреляции равен $0,80$ ( $\mathrm{P}<0,01)$. Выявлено также существенное различие в структурах факторов $\mathrm{I}^{\mathrm{a}}(\mathrm{x})$ и $\mathrm{II}^{\mathrm{a}}(\mathrm{T})-(-0,65$; $\mathrm{P}<0,05)$, а также $\mathrm{I}^{\mathrm{a}}($ т $)$ и $\mathrm{II}^{\mathrm{a}}(\mathrm{T})-(-0,66 ; \mathrm{P}<0,05)$.

Таким образом, выявлена комплементарность структуры факторов у хирургов и терапевтов, определяемая значимой отрицательной корреляцией первых и вторых факторов у хирургов и терапевтов, и значительное сходство $\mathrm{I}^{\mathrm{a}}(\mathrm{x})$ и I $^{\mathrm{a}}(\mathrm{T})$, детерминируемое значимой положительной корреляцией. Выявленное сходство структуры первых факторов у хирургов и терапевтов позволяет заключить, что изученные врачебные специальности характеризуются наличием обобщающего ядра, определяющего отношение врача (без учета специализации) к своей специальности. Интересным фактом является комплементарность факторной структуры внутри обеих специальностей. На наш взгляд, она свидетельствует о наличии взаимного дополнения общих свойств, характеризуемых первым фактором, специфическими для данной профессии психофизиологическими свойствами. Такая организация факторных структур позволяет адекватно учесть общие и специфические свойства личности у врачей разных специальностей. Здесь уместно подчеркнуть, что для хирургов важным оказывается восприятие и хранение информации, а для терапевтов формирование образа. Такое положение дел, по-видимому, связано с более конкретной деятельностью хирургов (непосредственный контакт с объектом), опирающихся в своей деятельности на восприятие и память, и опосредованным получением информации у терапевтов (анамнез, анализы, инструментальные исследования и др.), формирующих «образ болезни» по косвенным признакам.
Факторная структура отношения к социальным параметрам среды у хирургов и терапевтов представлена на рис. 2.

Из рисунка видно, что у хирургов выделены 3 фактора: $I^{6}(\mathrm{x})$ - фактор экономических ценностей и порядка, объясняющий $44 \%$ общей дисперсии, II $^{6}(\mathrm{x})$ - фактор гуманистических ценностей, детерминирующий $30 \%$ общей дисперсии анализируемых данных, и III ${ }^{6}(\mathrm{x})$ - фактор отношения к критике, детерминирующий $14 \%$ общей дисперсии анализируемых данных. В фактор I ${ }^{6}(\mathrm{x})$ входят характеристики отношения к материальным ценностям, к деньгам, к порядку, к трезвости, к принци-

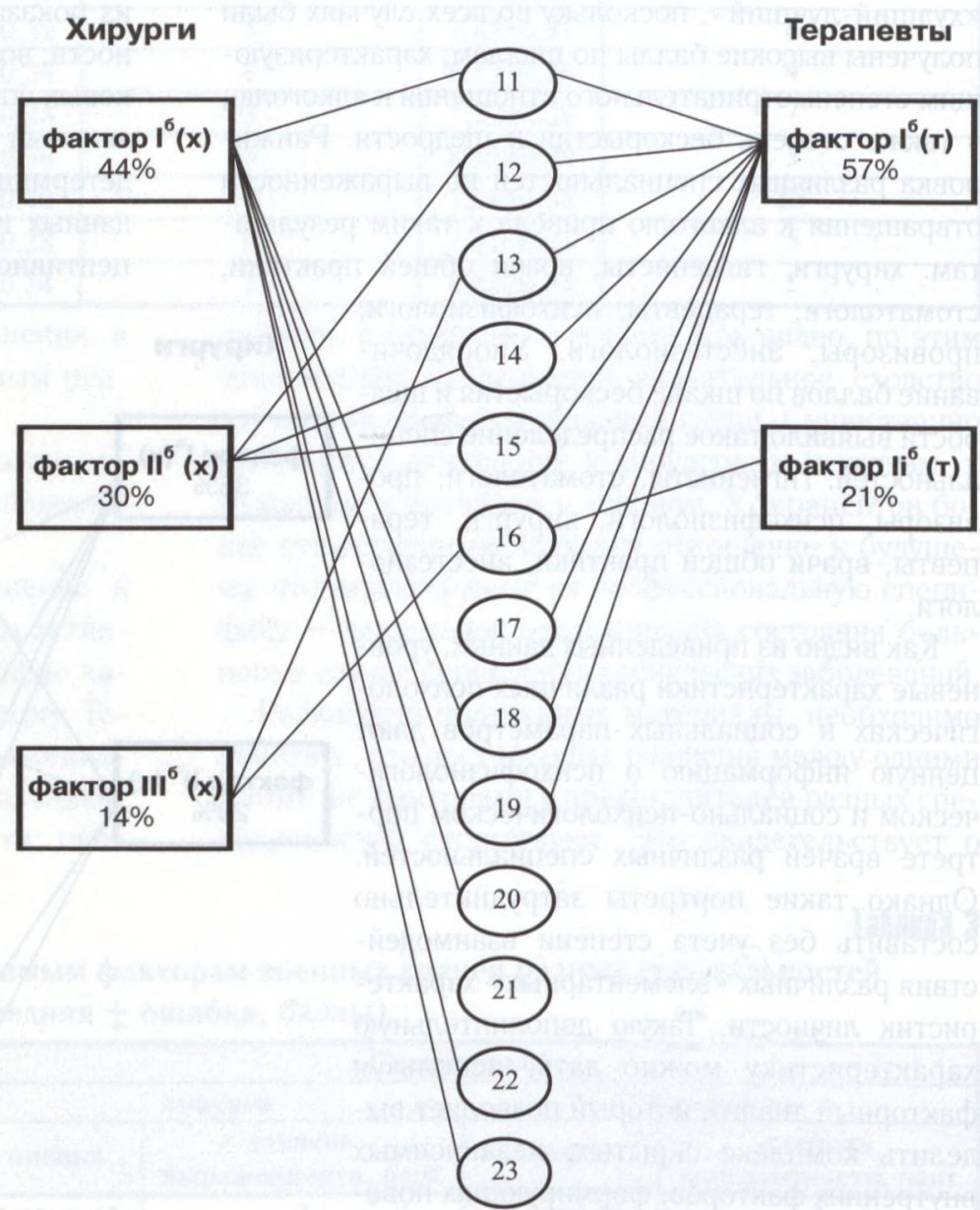

Рис. 2. Схема особенностей формирования скрытых профессионально важных комплексных факторов врачей хирургов и терапевтов по их отношению к сочиальным факторам.

11-23 - характеристики икал по отночению к социальным факторам, обозначенные в табл. 2.

$I^{6}(x)$ - фактор экономических ценностей и порядка у хирургов;

$I^{\sigma}(x)$ - фактор гуманистических ценностей у хирургов;

$I I I^{\sigma}(x)-$ фактор отношения к критике у хирургов;

$I^{\sigma}(m)$ - фактор гуманистических и экономических ценностей у терапевтов; $I^{6}(m)$ - фактор отношения к критике у терапевтов. 
пиальности, фактор II ${ }^{6}$ (х) представлен параметрами отношения к окружающим, к коллективу, к незнакомым, а фактор III $^{б}(\mathrm{x})$ состоит из характеристик отношения к себе и к критике.

Психо-социальный портрет терапевтов состоит из двух факторов: $\mathrm{I}^{\sigma}(\mathrm{T})$ - фактор гуманистических и экономических ценностей, объясняющий $57 \%$ общей дисперсии и формирующийся из показателей отношения к труду, к окружающим, к себе, к коллективу, к незнакомым, к общественной жизни и к деньгам; II ${ }^{б}$ (т) - фактор, названный фактором отношения к критике, который детерминирует у $21 \%$ общей дисперсии данных и состоит из характеристики отношения к критике.

При рассмотрении структуры первых факторов у хирургов и терапевтов необходимо отметить наличие определенных черт сходства (по отношению к труду, деньгам и материальным ценностям). Но по большинству параметров первые факторы различаются. Если у хирургов преобладают показатели, характеризующие упорядоченность и детерминированность действий (отношение к порядку, трезвости, принципиальности), то у терапевтов в этом факторе преобладает отношение к гуманистическим ценностям (к окружающим, себе, коллективу, незнакомым, общественной жизни). Это свидетельствует о большей направленности их деятельности на работу с психикой человека, в отличие от хирургов, которые на первый план выводят порядок в деятельности. Такая структура фактора у хирургов компенсируется вторым фактором, учитывающим гуманистические ценности (первый и второй факторы у хирургов комплементарны - парный коэффициент корреляции между этими факторами составляет $0,73 ; \mathrm{P}<0,01)$. Третий фактор у хирургов и второй у терапевтов во многом сходны по своему содержанию. Они учитывают то, что во врачебных профессиях многие решения принимаются коллективно, поэтому у медицинских работников наблюдается терпимое отношение к критике со стороны коллег.

Факторная структура отношения к собственным психологическим качествам у военных врачей представлена на рис. 3 .

У хирургов выделены 3 фактора: $\mathrm{I}^{\mathrm{B}}(\mathrm{x})-$ фактор влияния окружающих, объясня- ющий $27 \%$ общей дисперсии, II $^{\mathrm{B}}$ (x) - фактор влияния будущего, детерминирующий $18 \%$ общей дисперсии анализируемых данных, и $\mathrm{III}^{\mathrm{B}}$ (x) фактор уровня жизненной активности, детерминирующий $17 \%$ общей дисперсии анализируемых данных. В фактор $\mathrm{I}^{\text {в }}$ (х) входят характеристики отношения к неудачам, к опеке и указаниям, к суевериям, фактор $\mathrm{II}^{\mathrm{B}}$ (х) представлен параметрами отношения к будущему, к новому, а фактор III $^{\mathrm{B}}(\mathrm{x})$ представлен характеристиками отношения к принципиальности, любознательности и активности.

Психологических портрет терапевтов состоит из двух факторов: $\mathrm{I}^{\mathrm{B}}(\mathrm{T})$ - фактор жизненной перспективы, объясняющий $44 \%$ общей дисперсии и формирующийся из показателей отношения к будущему, к новому, к неудачам, к мужеству, к опеке и указаниям, к своему здоровью, принципиальности, любознательности и активности; II $^{\text {B }}$ (т) - фактор, названный фактором отношения к суевериям, детерминирует $14 \%$ общей дисперсии исследуемых

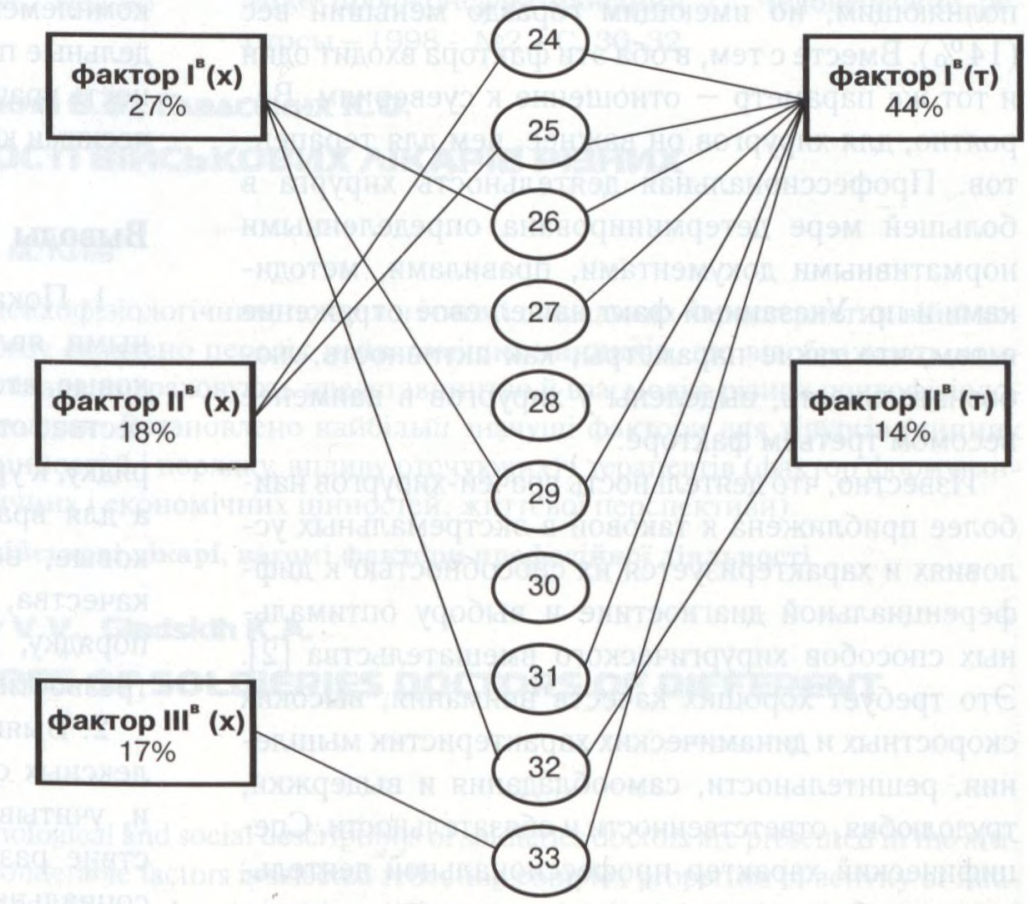

Рис. 3. Схема особенностей отношения к собственным психологическим характеристикам военных врачей.

24-33 - параметры отношения к психологическим составляющим трудовой деятельности, обозначенные в табл. 3.

$I^{B}(x)$ - фактор влияния окружающих;

$I^{B}(x)$ - фактор влияния будущего;

$I I I^{3}(x)$ - фактор уровня жизненной активности;

$I^{8}(m)$ - фактор жизненной перспективы;

$I^{B}(m)-$ фактор отношения к суевериям. 
данных и состоит из характеристики отношения к суевериям.

Наиболее весомые первые факторы у хирургов и терапевтов, как и в предыдущих случаях, имеют общие и различающиеся черты. Общие - отношение к неудачам и опеке. Поскольку контингент экспертов состоит из молодых людей, понятно их болезненное отношение к самостоятельности и устойчивости к неудачам. Можно предположить, что с возрастом это отношение несколько сглаживается. Особенно чувствительно такое отношение к влиянию окружающих проявляется у хирургов. Психика молодых терапевтов в большей степени направлена в будущее. Для них ценно отношение к новому, они любознательны, активны, адекватно относятся к своему здоровью. Еще одной особенностью описания первого фактора у хирургов является значительное сходство его структуры со структурой второго фактора у терапевтов (коэффициент корреляции факторных нагрузок $\mathrm{I}^{\mathrm{B}}(\mathrm{x})$ и $\mathrm{II}^{\mathrm{B}}($ т) равен 0,86 ; $\mathrm{P}<0,01)$. Это свидетельствует о том, что для терапевтов подобный по структуре фактор является дополняющим, но имеющим гораздо меньший вес (14\%). Вместе с тем, в оба эти фактора входит один и тот же параметр - отношение к суевериям. Вероятно, для хирургов он важнее, чем для терапевтов. Профессиональная деятельность хирурга в большей мере детерминирована определенными нормативными документами, правилами, методиками и пр. Указанный факт нашел свое отражение в том, что такие параметры, как активность, любознательность, выделены у хирургов в наименее весомом третьем факторе.

Известно, что деятельность врачей-хирургов наиболее приближена к таковой в экстремальных условиях и характеризуется их способностью к дифференциальной диагностике и выбору оптимальных способов хирургического вмешательства [2]. Это требует хороших качеств внимания, высоких скоростных и динамических характеристик мышления, решительности, самообладания и выдержки, трудолюбия, ответственности и обязательности. Специфический характер профессиональной деятельности требует от специалистов хорошего развития зрительного и двигательного анализатора. Терапевты должны иметь адекватное клиническое мышление, способность к дифференциальной диагностике заболеваний, выбору гибких, оптимальных программ индивидуального лечения. В структуре профессионально важных качеств терапевта должны быть представлены быстрое, критическое и гибкое мышление, способность к коррекции планов собственных действий, оригинальность, выдержку, высокий уровень ответственности за принятые решения и действия, хорошее развитие коммуникативных личностных характеристик, доброжелательности, отзывчивости, сочувствию и пониманию при общении с людьми.

Положительными сторонами представленного нами подхода к выделению профессионально важных качеств с помощью факторного анализа является получение обобщенных комплексных свойств отражающих деятельность врача и, учитывающих представительство и взаимодействие различных психофизиологических и психо-социальных характеристик человека. Такой подход позволяет не только перечислять, а затем по многочисленным методикам оценивать отдельные профессионально важные качества врача, но и определить вес каждого комплексного свойства личности, степень различия таких свойств у представителей различных медицинских специальностей, уровень завершенности характеристик личности, индуцируемый наличием комплементарных факторов, описывающих не отдельные профессионально важные качества, а личность врача в целом со всеми ее общими и специфическими компонентами.

\section{Выводы}

1. Показано, что у врачей-хирургов более важными являются: мыслительные, волевые, языковые, атенционные и сенсорно-перцептивные качества, отношение к другим людям, к труду, к порядку, к уровню трезвости, к общественной жизни, а для врачей-терапевтов - мыслительные, языковые, волевые, имаженативные, атенционные качества, отношение к другим людям, к работе, к порядку, к материальным ценностям, к уровню трезвости.

2. Выявлены наиболее весомые факторы комплексных свойств отражающих деятельность врача и, учитывающих представительство и взаимодействие различных психофизиологических и психосоциальных характеристик человека. Наиболее весомыми факторами для хирургов являются: фактор эмоционально-волевых качеств, фактор экономических ценностей и порядка, фактор влияния окружающих, для терапевтов фактор формирования коммуникативных возможностей врача, фактора гуманистических и экономических ценностей, фактора жизненной перспективы. 


\section{Литература}

1. Бричкова Т.П., Федоров Г.И. Фактор чувствительности пальцев рук в медицинских профессиях // Врачеб. дело.- 1998.- №7.-С. 135-138.

2. Быков И.Ю, Корзунин В.А., Петрукович В.М. и др. Сравнительная оценка профессионально важных качеств военных врачей в различных условиях деятельности // Воен.- мед. журн.- 2001.№8.- С. 65-72.

3. Карпіловська С.Я., Мітельман Р.Й., Синявський В.В. та ін. Основи професіографії: Навчальний посібник.- К.: МАУП, 1997.- 148 с.

4. Кундієв Ю.І., Чернюк В.І., Шевцова В.М. Напруженість праці як фактор професійного стресу та ризику здоров'ю // Укр. журн. з пробл. медицини праці.- 2005.- №3-4.- С. 90-98.

5. Лемешонок А.Ф., Мулява О.Д. Социально-психологические аспекты подготовки офицерских кадров / / Прикладная психол.- 1999.- №3.- С. 37-44.

6. Матюхин В.В., Шардакова Э.Ф., Юшкова О.И. и др. Воздействие факторов трудового процесса // Энциклопедия: Воздействие на организм человека опасных и вредных производственных факторов. Медико-биологические аспекты.- Т.1.- М.: Изд-во стандартов, 2004.- С. 344-441.
7. Молчанова О.П. Гігієнічна характеристика умов праці медичних працівників за основними медичними спеціальностями // Організація токсикологічної допомоги в Україні.- К., 2002.- С. 111-112.

8. Новиков В.С. Пути совершенствования профессионального психофизиологического отбора и психофизиологического сопровождения учебного процесса ВВУЗа // Воен.- мед. журн.- 2001.- №4.C. 9-14.

9. Сергета І.В., Молчанова О.П. Психофізіологічні і психологічні основи проведення професійної орієнтації та прогнозування професійної успішності учнів і студентів, що засвоюють медичні спеціальності // Сб. "Гигиена труда».- 2002.-Вып.33.- С. 126-136.

10. Усенко Л.В., Канюка Г.С. Зюков О.Л. и др. Профессиональный отбор как способ прогнозирования успешности и долгосрочности профессиональной деятельности анестезиологов // Укр. мед. часопис.- 1998.- №4.- С. 48-52.

11. Чиж И.М. Некоторые итоги и выводы из опыта медицинского обеспечения войск в вооруженных конфликтах // Воен.- мед. журн.- 2000.№6.- C. 4-15.

12. Шапаева Т. Опросник Майерс-Бриггс в практике профконсультирования // Человеческие ресурсы.- 1998.- №2.- С. 30-32.

\section{Ка^ьниш В.В., Єшенко В.І., Красовсыкий В.В., ГАаАсыких К.О. nсИХОФІヨІоһОГІЧНІ ОСОБАИвОСТІ вІЙСЬКОВИХ АІКАРІв РІВНИХ СПЕUААЬНОСТЕЙ}

\section{Українська військово-меАична акацемія, м. Київ}

У статті представлено матеріали вивчення психофізіологічних, психологічних і соціальних характеристик військових лікарів. За допомогою факторного аналізу складено перелік найвагоміших чинників, що відображають комплексні властивості діяльності військового лікаря та враховують представництво й взаємодію різних психофізіологічних і психо-соціальних характеристик людини. Встановлено найбільш значущі фактори для хірургів (чинник емоційно-вольових якостей, економічних цінностей і порядку, впливу оточуючих) і терапевтів (фактор формування комунікативних можливостей, гуманістичних і економічних цінностей, життєвої перспективи).

Ключові слова: психофізіологічні якості, військові лікарі, вагомі фактори професійної діяльності

\section{Kalnysh V.V., Eshenko V.I., Krasovskiy V.V., Gladskih K.A. PSYCHOPHYSIOLOGICAL FEATURES OF SOLDIERIES DOCTORS OF DIFFERENT SPECIALITIES}

\section{Ukrainian Military Medical Academy, Kiev}

Materials of study of psychophysiological, psychological and social descriptions of soldieries doctors are presented in the article. By the factor analysis the list of the most ponderable factors is selected reflecting complex properties of activity of military doctor, taking into account a representative office and co-operation different psychophysiological and psycho-social descriptions of man. The most ponderable factors are set for surgeons (factor of emotionally-volitional internals, economic values and order, influencing of circumferential), and internists (factor of forming of communicative possibilities, humanisms and economic values, vital prospect).

Key words: psychophysiological internals, soldieries doctors conducting the factors of professional activity

Поступила: 03.11.2005

Контактное лицо: Кальниш Валентин Владимирович, Украинская военно-медицинская академия, г. Киев 